Participatory Educational Research (PER)

Vol. 1(2), pp. 36-52, December, 2014

Available online at http://www.partedres.com

ISSN: 2148-6123

http://dx.doi.org/10.17275/per.14.08.1.2

\title{
Community Engagement Projects Executed According to University Policy
}

\author{
Soezin Krog*
}

University of South Africa, South Africa

\author{
Norma M Nel \\ University of South Africa, South Africa
}

B Ben-David

Forest Town School, Forest Town, Johannesburg, Gauteng. South Africa

\begin{tabular}{ll}
\hline \hline Article history & Universities play a critical role in communities by means of \\
Received: & community engagement which is considered a corner stone activity \\
& of higher institutions. One of the three focal areas on the University \\
Received in revised form: & of South Africa's (Unisa) 2015 agenda for transformation is the \\
04.08 .2014 & community engagement policy, expressed as "Towards the African \\
Accepted: & university in the service of humanity". This article illuminates \\
04.08 .2014 & aspects of Unisa's community engagement policy by way of two \\
& successfully completed community engagement projects. The first \\
Key words: & example consisted of a qualitative study which was undertaken at a \\
\hline Community engagement, Unisa & special school in Gauteng, for learners with severe intellectual \\
policy, Community & disabilities (SID). A "Learn not to Burn" mainstream curriculum \\
Engagement projects & was adapted to make it accessible for learners with SID. The results \\
& led to further community engagement activities. The second \\
& example relates to a qualitative, ethnographic study conducted in a \\
& rural area in Kwa-Zulu Natal with children with physical \\
& disabilities (CWPDs), exploring the negative influences of the rural \\
& community on them. Bronfenbrenner's bio-ecological systems \\
& theory was used to underpin the research. Ultimately the latter \\
& research led to an envisaged community engagement project. Based \\
& on the outcomes of the two successfully executed community \\
& research projects, we propose guidelines and success indicators for \\
future university community engagement projects.
\end{tabular}

Address for correspondence: Department Early Childhood Education. Email: krogs@unisa.ac.za 


\section{Introduction}

Community, as described by Hall (2010:25) is " a cluster of households or an entire region, as an organisation ranging from a provincial government department to a NonGovernment Organistation, a school, a clinic, a hospital, a church or a mosque or as a part of the university itself". Baradei and Amin (2010:109) state that because the word "community" has many implications, it could be referred to as "a network of shared interests and concerns". Communities can be based on different criteria such as geographic, ethnic and religious or even in relation to schools.

In light of the above definitions, higher education as a community benefits individuals by providing them with qualifications which result in high status employment and high lifetime earnings. In addition, universities offer private benefits to the corporate world by means of industry-sponsored research, journal articles and books which in turn profit commercial publishers; they benefit the public by providing access to education, skilling the workforce, contributing to economic growth, combating poverty, marginalisation and unemployment. Universities are part of the democratic process through the principles of institutional autonomy and academic freedom. They generate critique of economic and political power by educating a critical citizenry (Hall, 2010:27).

Based on the critical role which universities play in the communities, community engagement plays an integral role in the activities of higher institutions. Community engagement can thus be understood as a set of "public goods" which, for the purpose of this paper, emanates from higher education. For South Africa, this would mean addressing issues such as inequality, redressing inequities in the provision of education, housing, public health provision, countering HIV/AIDS and providing access to legal resources as a return on the investment of public funds in higher education (Hall, 2010:27). Community engagement can take on many forms such as distance education, community based research, participatory action research, professional community service and service-learning. "In its fullest sense, community engagement is the combination and integration of service with teaching and learning (e.g. service-learning), professional community service by academic staff and participatory action research applied simultaneously to identified community development priorities" (Council on Higher Education, 2006: 12).

The Draft White Paper on Higher Education (DoE 1997:8, 14-15, 32) states that although much is being done in the South African higher education system, it favours teaching and research policies, thus more needs to be done on regional and national levels to address the problems and challenges of the broader African context. One of the goals stipulated in the White Paper is that students need to become aware, promote and develop social responsibility of higher education, by way of community service, in social and economic development. At institutional level, it is important that higher education institutions have a social responsibility to the "common good" and this is done through the availability of expertise and the infrastructure of the institution for community service. As research is one of the focal areas at the University of South Africa (Unisa), it is thus an outcome of community engagement and is measured by peer-reviews, but also broader indicators, for example, on national level, national developmental needs, industrial innovation and community development.

The Council on Higher Education (CHE), Criteria for Institutional Audits $(2004: 3,6,9,19)$ focuses on two broad areas, namely the mission of the institution - linking planning, resource allocation and quality management and secondly, teaching and learning, research and community engagement. It is expected that attention should be given to transformational 
issues in the mission and goals of the institution, which include community engagement. Quality management should be integrated into the planning of the institution. Financial planning will ensure adequate resource allocation in order to develop, to improve and to monitor the quality of the institution's core activities, namely teaching and learning, research and community engagement. Academic support services are needed to provide for teaching and learning, research and community engagement needs. Community engagement takes place by means of service learning, institutional engagement with local and broader communities and should be part of the institution's quality management policy. It should also be linked to teaching and learning, research and should be effected by means of the allocation of adequate resources (policies and procedures should be in place for quality management) and institutional recognition. To make community engagement possible, adequate resources should be allocated in order to facilitate quality. Community engagement delivery and the effectiveness of quality related community engagement arrangements should be reviewed regularly. However, "the production of excellent graduates, cutting edge research and innovative community engagement programmes depends not only on the availability of efficient quality assurance mechanisms but also on the sustained nourishing of a community of students and scholars" (Council of Higher Education, 2006:3).

"The quality of community-university engagement is only as good as the quality of the individual partnerships through which the engagement is enacted" (McNall, Reed, Brown \& Allen, 2009).These authors believe, based on their research, that to co-create knowledge through effective partnership management and opportunities, conscious nurturing of practices need to be worthy of deliberate cultivation within community-university. A robust scholarship of engagement include valuing scholarship of engagement as legitimate scholarly pursuit; community engagement must be seen as an opportunity for research, with a substantive focus as well as the engagement; there must be an intentional orientation towards partnerships and plan for continuous assessment of the partnership process and the outcomes should be right from the beginning. Other elements include internal funding for community-based participatory research; fellowships for participating students and technical assistance when evaluating community-university partnerships (McNall et al., 2009:325, 327, 329).

There is a wide range of conceptualisations as to what community engagement is (in a university environment) and, in general, they include a number of activities such as curricular and extra-curricular activities and sometimes research activities (Hall, 2010:36). These activities are briefly discussed below, according to the Council of Higher Education (2006).

Student community engagement includes experiential learning, such as volunteerism, community outreach, internships, cooperative education or service learning. Volunteerism sees the students providing a service to the beneficial recipient community and the field of delivery is not necessary his or her field of study. It is an extra-curricular activity for which students do the fund raising by approaching donors. Clary and Snyder (1999:156-159) have identified six basic functions that are served by a volunteer namely to act on important values such as humanitarian express; to learn more about the world or exercise skills that are often not used; to grow and develop psychologically through volunteer activities; to gain careerrelated experience; to strengthen social relationships and to reduce negative feelings, such as guilt, or to address negative problems. Appeals for volunteers are most effective if they recognise that different individuals have different reasons for engaging in such activities.

Community outreach consists of students engaged in activities in order to provide services to a primary beneficial recipient community. Emphasis is placed on structure and commitment, 
as well as on student learning. These distinct projects are initiated by various departments of university faculties, who could provide recognition in the form of academic receiving credits or research publications.

Internships focus primarily on the students learning activities, wherein they gain hands on practical experience which enhances further understanding of their field of study, the achievement of learning outcomes and gaining vocational experiences. Internships are fully integrated into the student's curriculum (e.g. psychology, social work and teaching).

Cooperative education programmes focus primarily on the students and learning.Programmes are co-curricular in nature, providing related opportunities, but not necessarily integrated with the curriculum. Students are placed within the industry to enhance and enrich their understanding of the area of their study.

Service-learning sees students and community engaged in activities as primary beneficiaries. The primary goal is to provide community service as well as to enhance student learning. Community service is integrated with scholarly activities such as learning, teaching and research. It sees scholarly activities and community services being enriched vice versa by the engagement.Service learning proposes the development of high education in relation to the needs of the community (Council of Higher Education, 2006:15)

It should be noted that "The quality of community-university engagement is only as good as the quality of the individual partnerships through which the engagement is enacted" (McNall et al., 2009). This article provides a conceptual framework for community participation in education from a particular university perspective.

\section{Unisa's Community Engagement and Outreach Policy}

The Unisa 2015 agenda for transformation,"Towards the African university in the service of humanity" is a characteristic of an engagement with society. The focus is on improving research and teaching and learning with the main aim of serving the community by providing experiential learning, knowledge application, career opportunities, knowledge creation and academic discourse (Unisa CE and Outreach policy, 2008:8).

The aims of community engagement and outreach include a variety of essential aspects. Outreach to communities in need should be on a volunteer basis, nurturing and promoting the community. Best practices should be promoted such as the integration of curriculum-based community engagement with teaching, learning and collaborative research and recognising the valid pedagogy found in scholarship of community engagement. Sustainable partnerships with communities should be established by regulating community engagement and outreach and establishing principles for planning, implementing, monitoring and evaluating community and outreach activities as well as promoting, recording and coordinating community engagement and outreach (Unisa CE and Outreach policy, 2008:8)

Within Unisa's community engagement and outreach policy, community engagement is defined as "initiatives and processes through which issues relevant to its community are addressed by means of community engagement and outreach". Community engagement finds expression in a variety of forms, such as informal and relatively unstructured activities to formal and structured academic programmes. "Community engagement is a two-way interaction between the university and the community with which the university forms partnerships that yield beneficial outcomes for both the community and the university" (Unisa 
CE and Outreach policy 2008:8). Whereas community outreach is a "voluntary outreach to communities by academics, university employees, alumni or students in response to the social, economic and political needs of the communities. It is also seen as a one-way initiative from the university, its students and alumni to communities". Community-based or curricular community engagement on the other hand is defined as "teaching, learning, and scholarship, which engages academic staff, students, and the community (service sectors) which is mutually beneficial as well as a respectful collaboration".

\section{Principles regarding community engagement and outreach.}

This entails teaching, learning and research as the core functions of community engagement and outreach on a university level. Social, environmental, economic and cultural development of a community is promoted which is a mutually beneficial interaction between Unisa and the community. Collaborative development of academic programmes and research projects which enable partnerships and relationship building is engendered. Through community engagement and outreach the curriculum, teaching and learning and research are contextualized, enhanced and enriched by means of consultation with the community. By determining institutional parameters to monitor and evaluate community engagement initiatives they can be incorporated into a strategic resource allocation model.

Community engagement projects are seen as community needs driven and aligned to Unisa's needs regarding teaching, learning and research. The assessment of community engagement has to be linked to theory and practice, including an annual evaluation of community engagemnt in teaching and its impact in the effectiveness of community engagement.

Curriculum related community engagement is offered through formal accredited programmes (certificates, diplomas, degrees, short learning programmes) and the purpose being service learning. Both the students and the community are primary beneficiaries. Non-curriculum related community engagement initiatives benefit both the community and the employees. However, there is no link between curriculum and research. There is no financial gain that is provided except if an honorarium is paid. Research-related community engagement is a scientific knowledge which is advanced due to community engagement. The research capacity of the university is utilised to address the community's problems while the community act as a partner. Research is opportunity-driven with the aim of community development and capacity building aimed at skills and social development.

On the other hand, community outreach is not considered a core function and it is effective if it enhances Unisa's image. All outreach programmes need to be monitored by the department/centre/institute/region involved. It remains voluntary outreach (one-way initiative) by academics, students, alumni and staff to communities in response to social, economic and political needs.

Unisa's CE and outreach policy needs to link with existing policies such as the tuition and research policies. Formalised quality assurance arrangements need to be in place and community engagement must be integrated with those of teaching, learning and research. Research proposals involving community engagement must be submitted to research committees for approval and there must be a budget for all community outreach initiatives. 


\section{Development and delivery of $C E$ and outreach programmes}

This consists firstly of the conceptualisation phase, which requires the determination of the community needs, building teams and partners, developing curriculum in collaboration with community leaders and service agencies in order to integrate theory and service as well as conducting a feasibility study. Secondly, the implementation phase is required to prepare students for the community engagement projects. This entails equipping them with knowledge regarding negotiation techniques, research methods, mentoring, logistics, resources and allocation. A third most important consideration in the implementation phase is ethical requirements. The policy on Research Ethics needs to be applied for community engagement and outreach. Fourthly, the impact of community engagement and outreach needs to be determined in order to ascertain the partner and community satisfaction; changes in the quality of community life resulting from community engagement and outreach; changes in the quality of learning and research.

\section{The teaching and learning functional plan of Unisa (February 2012)}

This plan includes fostering active community engagement that enables the establishment of partnerships and collaborations with relevant stakeholders and the opportunity to do community engagement across the country. There is a further necessity to grow community engagement initiatives. Various strategies have been envisaged, namely refinement of the scope and the extent of community engagement in context of open and distance learning (ODL), which includes meeting the 2015 target of at least six community engagement projects per college; developing a community engagement impact assessment by 2014 and community engagement quality management system by 2014; developing a funding model for community engagement by 2013, which will be implemented in 2014. A further strategy includes building an enabling environment for community engagement. The need has been identified to build community engagement partnerships by 2013 and an impact assessment will be done in 2015 .

Seeing that the main focus in this paper is on community engagement within the education sector. Baradei and Amin (2010:113) look at the community approach to education as it is the main component of the "emerging paradigm for inclusive education", which is dominant in primary education reforms. It incorporates seven main principles. namely the right of all children to primary education; a child-centred approach to education; quality improvement; providing for responsive education; provision is a shared responsibility that means that schools are considered an integral part of the community; recognition of diverse needs and committing to a holistic approach to education. Dreyer (2008:82) explains that the emphasis on ensuring social justice for all learners is growing as the focus is on developing autonomy.

The presenters have a galvanised concern about the state of education in South Africa and this mobilised them to address the problem by making adaptations to a mainstream curriculum for students with severe intellectual disabilities. To understand a community engagement project in terms of the community involved, the authors present a community engagement project titled: "Differentiated instructional practices teachers employ to teach a specific curriculum to learners with severe intellectual disabilities", which was initiated in 2010 and completed in 2011. This project is aligned with the Unisa Community Engagement and Outreach policy. Similarly, a doctoral student gives an account of her research study she conducted in rural Kwa-Zulu Natal titled "The impact of negative influences facing children with physical disabilities in rural areas" and how it led her to become involved in community engagement. 


\section{PROJECT 1 (Completed according to Unisa's research related community engagement) \\ Differentiated instructional practices teachers employ to teach a specific curriculum to learners with severe intellectual disabilities}

\section{Introduction}

South Africa has embraced inclusion and, in doing so, adopted principles guiding the transition towards greater inclusion. These principles are based on the international declaration: "Education for all" (UNESCO, 2005:13), the Constitution of the Republic of South Africa (1996), the South African Schools Act 84 of 1996, Education White Paper 6 (Department of Education, 2001) and Guidelines for full Service/Inclusive Schools (Department of Basic Education, 2009). In moving towards greater inclusion, attention is drawn to a flexible system in which the needs of a diverse population is served as inclusively as possible (Department of Education, 1999). Furthermore, White Paper 6: Special needs education (Department of Education, 2001) perceives an inflexible curriculum as "the most significant barrier to learning" and argues in favour of a flexible curriculum.

The "Learn not to Burn" community project was conducted over a period of 12 months in the context of a public special school in Gauteng. The school caters for learners with severe intellectual disabilities, however there are learners who have multiple disabilities.

\section{Research objectives of Project 1}

The objective of this research was to describe teachers' and therapists' perceptions of and insights into their experiences of teaching a differentiated curriculum and using differentiated instructional practices. A qualitative research design was used in this research pilot in order to learn about the views of the participants and to report their stories, building and understanding from the ground up in their context and setting (Creswell, 2007). A descriptive design, ethnography was employed which concentrated on the behavioural regularities and the interaction between people, within a group/s in a community/organisation (Welman, Kruger \& Mitchell, 2008:193). Contextual validity by means of triangulation was ensured with the use of photographs, video clips of participants whilst engaging in activities as well as focus group interviews, completion of questionnaires and journal analysis by teachers and therapists.

\section{The Early Childhood Development Institute's learn not to burn inclusion community and research project}

The "Learn not to Burn" (LNTB) inclusion project was the initiative of the Early Childhood Development Institute (ECDI) of the Gauteng Department of Education in collaboration with Unisa, the Johannesburg Emergency Services and the special school. During the inclusion, research project valuable partnerships were established between a special school in Gauteng, Unisa and the Johannesburg Emergency Services. During the research, the programme entitled "Learn not to Burn", a pre-foundation, mainstream burn prevention programme, was adapted and implemented to suit the needs of learners with severe intellectual disabilities (SID).

Consultants and relevant stakeholders originally developed the LNTB programme, and endorsed by the World Health Organization and implemented in the 1960's in the USA. The programme has proven to be the most successful in the USA and therefore in the 90s, this 
programme was adapted to suit the specific South African context. Although statistics indicate that Africa has one of the highest burn mortality rates in the world and that $77 \%$ of structural fires take place in residential properties, limited fire safety training is provided to learners in South Africa. The ECDI has recognised the problem fire related accidents pose to young learners and has therefore taken a decision to drive the programme in South African schools. This LNTB programme consists of ten lessons, focussing on fire safety education which contain essential and practical life skills such as awareness of dangerous situations in and around the house as well as emergency phone numbers. The LNTB programme is designed in such a way that learners can be equipped with knowledge and skills related to fire safety and to change learners' behaviour when they are confronted with to deal with an emergency related to fire.

Before the project could be initiated, the researchers prepared a proposal which was tabled at the university school of education, in order to accept it as a feasible project. The following aspects were taken into consideration and a full description of each was prepared.

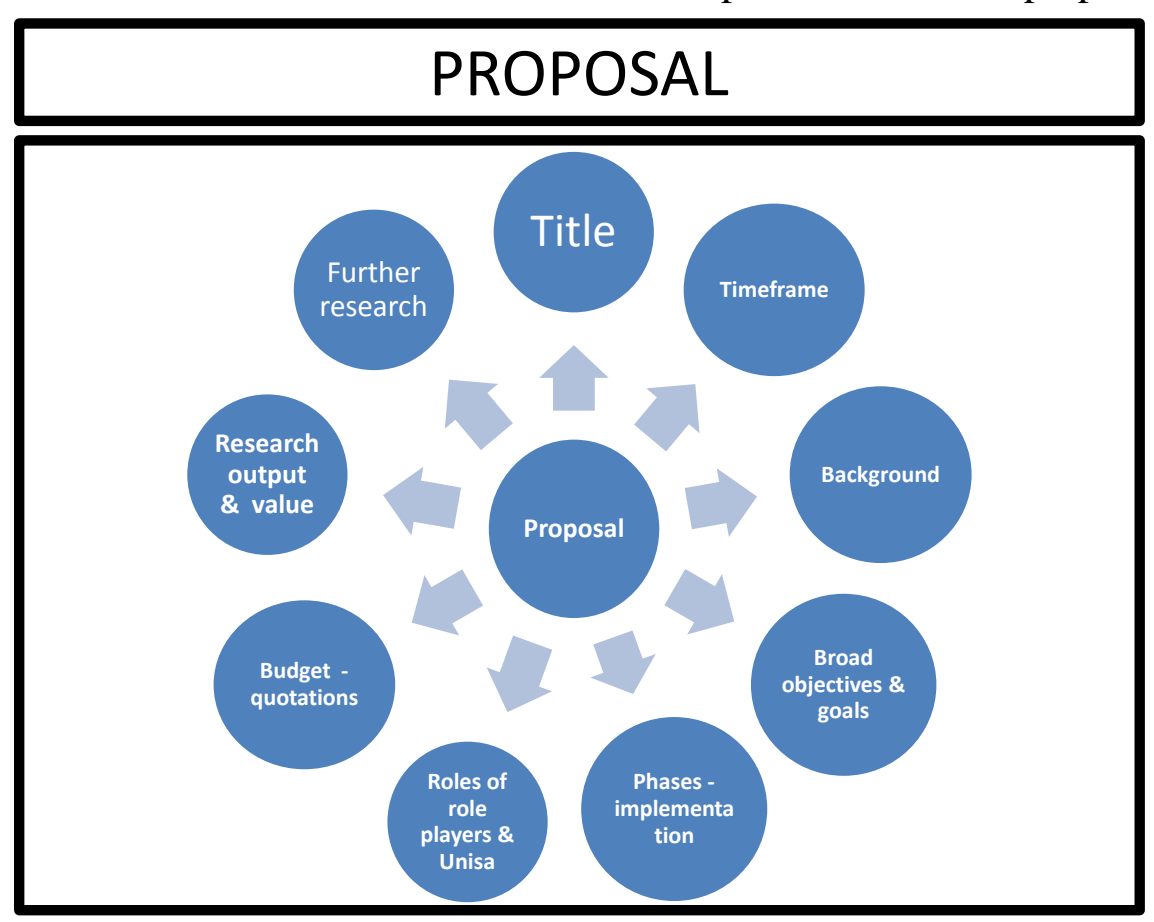

Figure 1: Proposal for the LNTB community engagement project

During the LNTB community and research project, the ECDI, Unisa and the Johannesburg Emergency Services were available and present to offer advise and consult with teachers and therapists. Meetings were frequently held with the principal and deputy principal to monitor the progress of the implementation of the LNTB differentiated curriculum. The teacher and therapist activities, the collaborative meetings held on a regular basis as well as individual interviews with the teachers and therapists were captured in field notes by the principal of the school as it contributed in the writing an article which was published in an accredited journal as well as the writing up of her doctoral thesis. The activities included teachers' use of a variety of teaching strategies to teach the ten fire safety lessons. In addition they to resorted to scaffolding, that is to break the lessons up into steps which learners could manage; to make use of repetition in order to grasp, which to the learners with SID, were experienced as difficult concepts and importantly to harness the learners senses such as the visual modality 
and to combine it with play activities. By making the activities practical and hands-on made it easier for the learners to remember facts and to apply the skills and knowledge they had learnt more easily.

In order to enforce the safety messages of each lesson and to promote understanding of the concepts (in particular for non-verbal learners and those who have limited speech and speech inpediments), the teachers and therapists combined songs with movement, art, poetry, games and drama. To promote language development, vocabulary extension exercises were incorporated in each lesson. The use of pictures accompanied by the spoken word was imperative to enable the teachers and therapists to convey the messages of each lesson.

To teach social skills and etiquette, the teachers and therapists made use of group activities. They also needed to make specific adaptations to the physical and social environment by for example enlarging (in bold) the print accompanied by simple pictures on worksheets. The classrooms had to be organised in such a way that the furniture was place in a way for wheelchair accessibility. All these efforts demanded innovation and creativity from the teachers and therapists in their quest to appropriately and effectively differentiate the curriculum for the learners with SID to access the LNTB curriculum. Learners interests, learning styles and strengths as well as differentiated teaching methods, learner support materials and assessment processes had to be considered at all times when devising the lessons.

These efforts which were made to differentiate the curriculum by making appropriate adaptations and accommodations proved to be successful and to the benefit of the learners with SID. The ten fire safety lessons were successfully taught as the learners could demonstrate their understanding and apply their knowledge of the ten core fire safety messages.

The project was conducted in the following phases:

Table 1: The phases in which the LNTB community engagement project was executed

\begin{tabular}{|c|c|c|}
\hline PHASES & PROCESS & CONTENT \\
\hline Phase 1 & Identification/Selection & $\begin{array}{l}\text { - } \text { Problem Identification } \\
\text { - } \text { Project goal } \\
\text { - } \text { Context } \\
\text { - } \text { Role players }\end{array}$ \\
\hline Phase 2 & Planning & $\begin{array}{ll}\text { - } & \text { Writing a CE proposal \& presentation to College Management } \\
& \text { Committee } \\
\text { - } & \text { Registering of CE project \& ethical clearance and permission } \\
\text { - } & \text { Research plan } \\
\text { - } & \text { Management plan (research plan, budget, resources) } \\
\end{array}$ \\
\hline Phase 3 & Implementation & $\begin{array}{l}\text { - Execution of planned activities (research activities \& } \\
\text { skills/knowledge sharing) } \\
\text { - Addressing needs }\end{array}$ \\
\hline Phase 4 & Finalisation & $\begin{array}{l}\text { - } \text { Research findings \& conclusion } \\
\text { - Writing of academic article } \\
\text { - Presentations \& conferences (upcoming conference at Unisa } \\
\text { "Exploring community engagement trends in an African } \\
\text { developmental context" 22-23 March 2012) }\end{array}$ \\
\hline
\end{tabular}

\section{Conclusion}

In this study, the benefits for the school community were based on differentiating the LNTB curriculum by making the appropriate adaptations and accommodations in an effort to 
cater for learners with SID. As the teachers and therapists were challenged to be creative and innovative in preparing hands-on practical activities and providing instructional adaptations, accommodations and differentiation of the "Learn not to burn" fire safety programme it contributed to the enhancement of the pedagogy of the school as the individual teacher's knowledge and skills in curriculum differentiation were developed.

An outcome of the research project, which is not reported in this article, was the training of teachers at six neighbouring special schools (at the special school where the research was conducted) on how adaptations and modifications of the LNTB curriculum, as it pertains to their specific context, could be done. The Unisa researchers, in their advisory and research capacity, attended most of the training sessions which took place twice a month during 2012. The adapted LNTB curriculum was also integrated in the Early Childhood Development (0-4 years) curriculum for the Gauteng Department of Education and training of this curriculum for practitioners will take place in the near future.

The findings of the study have further implications for research in the field of early childhood development, curriculum differentiation and teacher training. However, the researchers, would need to look at other special schools which cater for students with different disabilities, such as autism, blindness, cerebral palsy and deafness, as there are further challenges faced by teachers in differentiating the curriculum for these learners.

In conclusion, an important finding of the LNTB research project is that the involvement of Unisa led to the building of valuable partnerships in education. The symbiotic partnerships established during the research programme served as an example in which theory and practice were integrated in order to enrich the learning experiences of students with SID. Through effective partnerships, with the ECDI, the special school participating in the research and the other schools which came on board the training by this school as well as the Johannesburg Emergency Services has led to continued collaboration. This happens in the form of a stakeholders forum where various stakeholders meet and network to further the interests of the ECD sector of education and to table concerns which can be taken to the Department of Education policymakers and authorities via the ECDI. Conferences and seminars are also held as a platform to share with stakeholders, important issues regarding ECD. The researchers are convinced that this project was in line with Unisa's community engagement policy.

\section{Project 2}

\section{Community engagement in the rural areas of South Africa and Urie Bronfenbrenner's Bioecological model}

I, Brenda Ben-David, graduated as a PhD in 2012 at Unisa. The title of my thesis is "The impact of negative influences facing children with physical disabilities in rural areas". It is as a result of my rich experiences doing qualitative and ethnographic research that I have realised the importance of community engagement in our rural areas. Purposeful sampling (Creswell, 2007:125) was used to select members of the community, peers, teachers, family members, the community leader, sangomas (witch doctors) and children with physical disabilities (CWPD's) aged 6-9 years. Forty participants were selected and consent was obtained from the participants. Ethical clearance was granted by Unisa. The research was conducted in four rural areas in the Estcourt town vicinity, KwaZulu Natal. A local community based rehabilitation worker negotiated Entrée to the field and the skills of a gatekeeper was employed to do all the translations in the the interviews. The data collection 
instruments (which was done with and for the community) were observations of CWPD's in school and out of school, questionnaires completed by teachers, interviews conducted with community members, peers, teachers, family members, the community leader, sangomas (witch doctors) and children with physical disabilities (CWPD's), photographs of homes, schools, lack of resources and any other areas relevant to the study and drawings of CWPD's. I lived in the community in order to observe and experience rural life. An analytical approach of data analysis was used for the qualitative study (Watt, 2007:95) and two independent coders were used to code the data and to identify the major themes and categories.

The theoretical framework used in this study was that of Urie Bronfenbrenner's bioecological model which is a wonderful and powerful framework for community engagement in our rural areas. A bioecological view of community development is and can be created within the psychological, social, cultural, educational, physical and economic conditions that surround the community's lives in the rural areas. Communities provide the template for most of these conditions and therefore community engagement enables communities to participate in order to optimise opportunities for all.

\section{BRONFENBRENNER'S BIOECOLOGICAL PERSPECTIVE ON THE INCLUSION OF CHILDREN WITH PHYSICAL DISABILITIES}

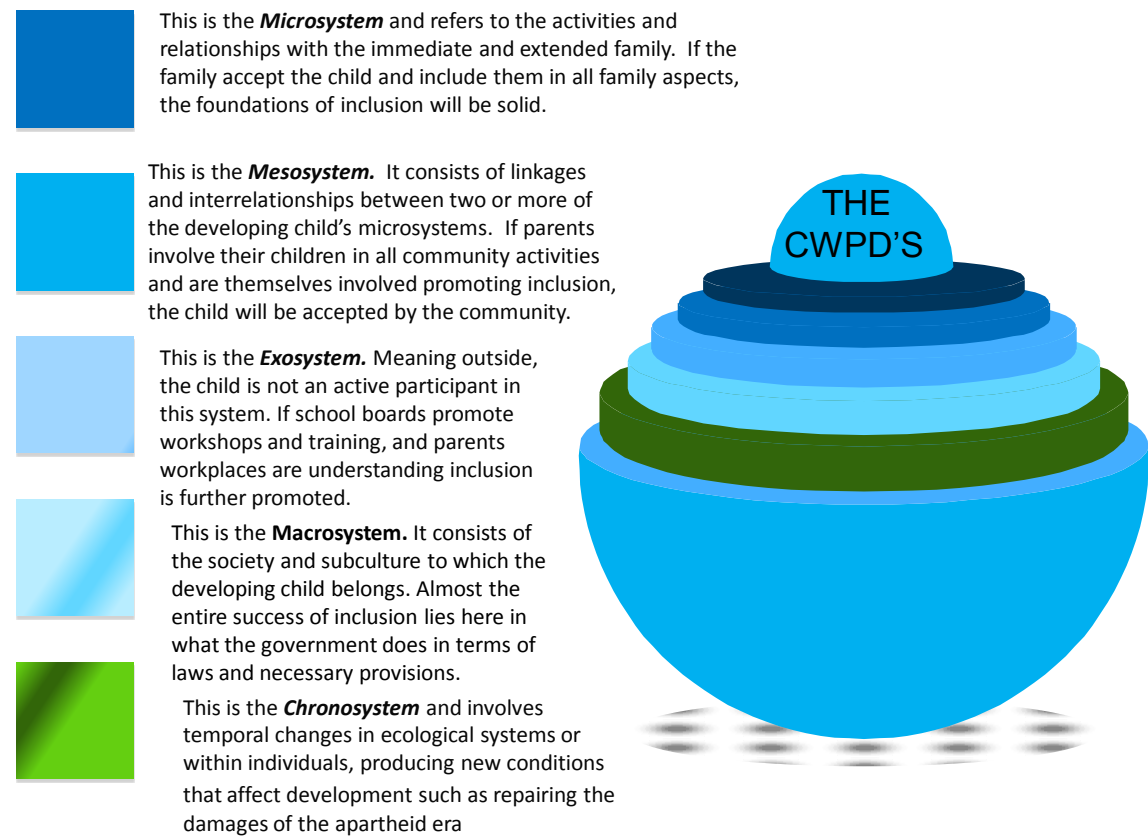

Figure 2: Bronfenbrenner's bioecological perspective on the inclusion of children with physical disabilities Source: Ben-David (2012)

Community engagement in the rural areas is integral to the child's healthy development. Community engagement is central to community life in which information, services and resources converge on the one common goal of Unisa and that is helping all children to reach their developmental potential. Although family cultural factors and behaviours are major determinants of a healthy development, community engagement adds to the backdrop for this healthy development that is so needed in all areas of children's lives. Community engagement 
will nurture connectedness through features of the physical landscape such as lack of roads, lack of facilities such as recreational facilities and libraries and opportunities for community interactions, attitudes of inclusiveness and tolerance. In addition, by looking at the exosystem and macrosystem levels on Bronfenbrenner's model (to be discussed later) and support services that are geared towards empowering the community and capacity development this connectedness is enhanced.

Community engagement nurtures the type of social climate in which people in the community tend to share goals, bond together to build their capacity and resilience in the face of the economic hardships of unemployment in the rural areas. These social networks of the community engagement need to be goal-directed. It was important to me to understand the breadth of community factors that can provide support for all the community. This could not have been achieved without having immersed myself in this ethnographic study as a Unisa student.

Briefly, Bronfenbrenner's framework examines all influences on children's development, including parenting, family, school, community and two levels in which the child is not directly involved such as the school boards, municipalities, and the government that needs to bring out policies and laws which prevent aspects like discrimination and needs to ensure that all facilities such as clinics are both functional and funded. Since it was first introduced by Bronfenbrenner in 1979, the bioecological model contends that human development takes place through progressively complex, regular, reciprocal interaction between the child, persons, objects and resources that are available in the community. This perspective situates the community as the most powerful setting for the development of the child. The promise of good health and opportunities beyond primary school lies with parents who can meaningfully be engaged with the possibility of active community engagement. Unisa is instrumental in helping some communities by allowing its doctoral students to them to discover their needs. It was through this opportunity that I was able to identify the need for support and social interactions which is so essential in the rural communities as I realized that community engagement provides platforms for social interactions which can be empowering and help to sustain the community's viability.

It was through my interactions with the members of the community that I understood their need for self empowerment. None of them wanted to rely on government support or charities. One member of the community said, "We just need a chance, we want to be our own bosses. This will give us and our children respect. I felt like my heart was bleeding blood when I found out about my son he must have a chance his heart must not bleed blood one day, Please Brenda come back and help us. I promise we will work hard we just need a chance to get us going".

There are so many examples of my engagement with the community. I spent a week with grade 7 learners aged 13-17 years. They did not understand disability and did not want to have CWPDs involved with the exception of one or two learners. I asked one of the learners why she did not want to have a friend with a disability. The learner answered,"They sit on wheelchairs". I told the learners not to discriminate against people with disabilities. I also explained to them the expertise that wheelchair learners could have. Learners need some form of community engagement to understand that CWPDs are not useless.

After the discussion, one learners was still adamant that he could not have a child in a wheelchair as a friend as they could not run and play soccer. I then told him that all soccer 
teams need someone to keep score, to keep track of fouls and those cheating and to hand out oranges and drinks at half time. The learner smiled at me and replied, "Oh yes! That's a good idea".

The time I spent with the learners intensified my strong belief that community engagement is so crucial and I am grateful that I had the opportunity to go to remote areas and change negative perceptions.

The mainstream teachers at the school were apprehensive about CWPDs after I had handed out questionnaires to them, but were grateful when I suggested my model. I had to visit a centre to watch and learn how to best accommodate learners with physical disabilities. The principal of the school asked me, "When can you come and help and teach us?"

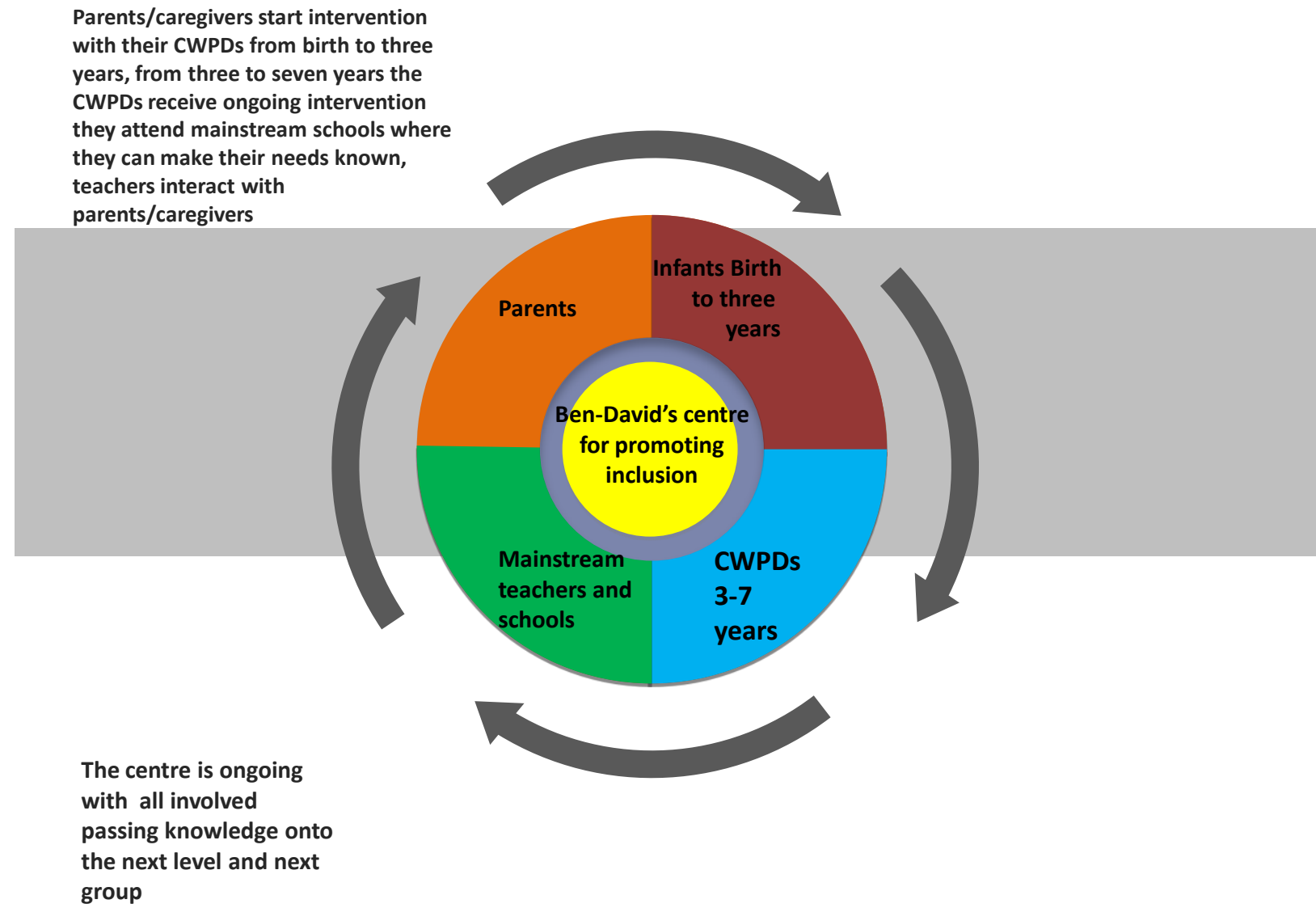

Figure 3: The ongoing cycle of intervention for CWPDs in the rural areas.

\section{Source: Ben-David (2012)}

I came across a centre that was set up by a computer company for children to learn to use computers. They were not sure at the centre how they could accommodate CWPDs. We discussed at great length how and why it should be done and my gatekeeper begged me to help. I also met with the chief and induna (chief's helper). They were prepared to offer us land if only we could come and help. I also met with the ward councillors and the mayor They all loved the idea of the "community model" and were keen to be involved.

There are lot of opportunities in ALL rural areas for community engagement. It is crucial and 
morally obligatory for an institution such as Unisa to be involved in community engagement. When I started with this project, I never thought I would become passionate about it and want to pursue it.

Below are illustrations of children who were sexually abused (cf. Figure 4). One drawing shows the detrimental effects of HIV/AIDS felt by a six-year-old girl who does not have a father or a mother. She has got a baby and is sad. Included is also a photograph which illustrates the remoteness (cf. Figure 5) and the need for my envisioned centre which is an example of Bronfenbrenner's idea of community engagement.
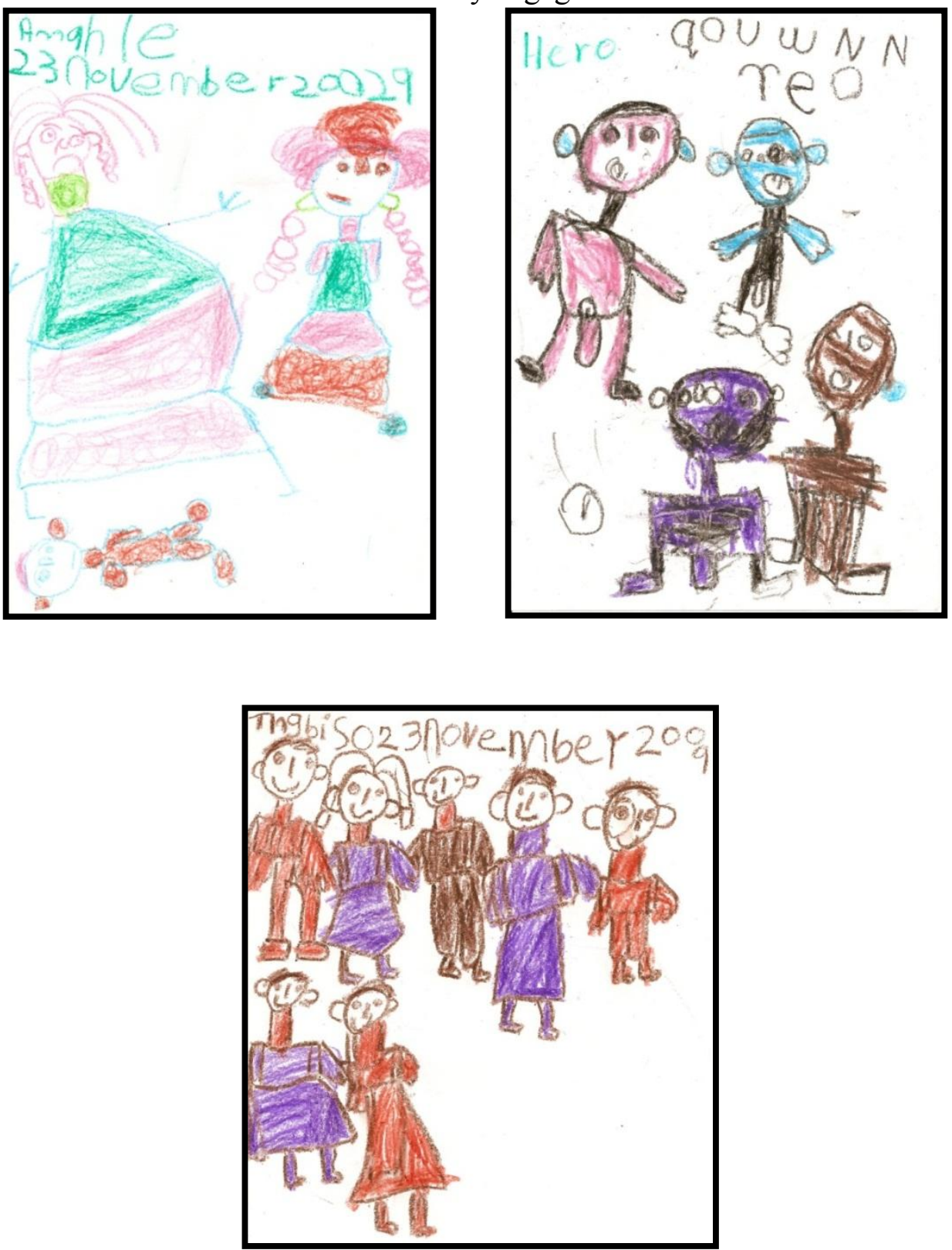

Figure 4: Illustrations of sexually abused children 


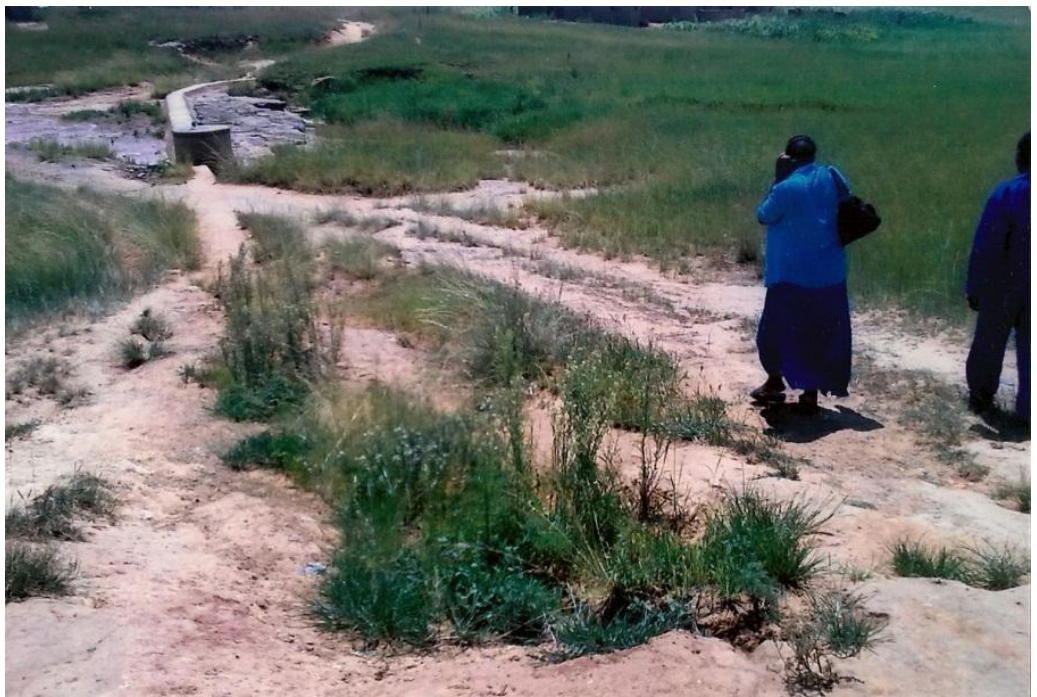

Figure 5: The remoteness of a rural community

In conclusion, it is imperative for Unisa to continue to encourage research that would keep the needs of ALL children in rural areas on the agenda for policy and assist in planning for the exo and macrosystemic levels. This can be done by encouraging Masters and Doctoral students as well as academics to engage with the community through community engagement projects. This is in line with the Unisa Community Engagement Policy. A community engagement project will form part of the community engagement requirements of for example the College of Education; it will contribute to effecting change in the quality of community life; it will also contribute to enhancing formal accredited programmes, teaching, learning and research based on the results of the research in the community; it will also promote social, environmental, economic and cultural development and lastly it will ensure best practices through the integration of curriculum-based community engagement with teaching, learning and collaborative research.

Finally, community engagement should become the responsibility of all members of the community who wish to improve the quality of their lives.

\section{Recommendations}

The following recommendations and advices for the CHE and the Minister of Education are offered in Hall (2010:48) and need to be adhered to by Unisa staff: a revised policy aligning engagement with the third sector (civil society which is located between the family, the state and the market) of the university's core functions, namely teaching and research; provide incentives through state subsidy for teaching which will ensure that models of good practice for service learning are established and resourced to be an integral part of teaching and learning in higher education; third sector engagement should be an integrated part of teaching and research [Higher Education Quality Committee (HEQC) to revise the audit criteria]; that the National Research Foundation allocate funding for research about third sector engagement for case studies of good practice in third sector teaching and research.

With a view to become involved in UCECE's (Unisa Centre for Early Childhood Education) envisaged projects, it is important to use the success of the LNTB community engagement project, it's preparation of the proposal and gauging it's outcome against success indicators 
underpinned by the Unisa Community Engagement and Outreach Policy (2008), to follow suit.

Answers to the following questions would have been indicative of how successful community engagement projects were:

- Did the staff and/or students and the beneficiaries have a common agenda?

- Did the CE project have the potential to scale?

- Was the project sustainable beyond the project?

- Were the staff and/or students agents of change and were they able to mobilise the communities?

- Were value systems and attitudes addressed at all levels?

- Was awareness created, for example, disability awareness?

- Whose needs and whose agenda were addressed?

- In the case of education, a rights driven approach was taken?

Further research needs to be conducted simultaneously while the current and envisaged projects are in progress in order to establish the impact that the training and other interventions have made and how sustainable they are.

\section{Acknowledgements}

Dr M. Kempen Principal at the school where the LNTB project was executed.

\section{Bibliography}

Ben-David, B. 2012. The impact of negative influences facing children with physical disabilities in rural areas. $\mathrm{PhD}$ thesis, Unisa.

Bronfenbrenner, U. 1979. The Ecology of Human development: experiences by nature and design.MA: Harvard University Press.

Baradei, LE \& Amin, KZ. 2010. Commuinity participation in education: a case study of the boards of trustees' experience in the Fayoum governorate in Egypt. Africa Education Review 7(1):107-138.

Clary, EG \& Snyder, M. 1999. The motivations to volunteer: theoretical and practical considerations. Current Directions in Psychological Science8:156-159.

Council on Higher Education. 2004. Criteria for Institutional Audits, June 2004. Higher Education Quality Committee p i-27.

Council on Higher Education. 2006. A good practice guide and self-evaluation instruments from managing the quality of service-learning. Higher Eucation Quality Committee. June, 2006. P i-70.

Creswell, J.W. 2007. Qualitative inquiry and research design: choosing among five approaches. London: Sage.

Department of Education (DoE), 1997. The Draft White Paper on Higher Education. Pretoria.

Department of Education 1999. Consultative Paper No.1 on Special Education: Building an Inclusive Education and Training System, First Steps. Pretoria: Government Printers.

Department of Education (DoE). 2001. Education White Paper 6.Special Needs Education. Building an Inclusive Education and Training System. Pretoria, Elsen Directorate.

Department of Basic Education (DBE) 2009. Guidelines for full-service/inclusive schools. Pretoria:Department of Education. 
Dreyer, LM. 2008. An evaluation of a learning support model in primary schools in the West Coast/Winelands area. Doctoral Thesis, Stellenbosch University.

Hall, M. 2010. Community Engagement in South African Higher Education. Kagisano no 6, January 2010.

McNall, M, Reed, CS, Brown, R\& Allen,A. 2009. Brokering community-university engagement.Innov High Euc 33(5):317-331.

United Nations Educational, Scientific and Cultural Organization (UNESCO), 2005.

Guidelines for Inclusion: Ensuring Access to Education for All. UNESCO 7, place de Fontenoy, 75352 Paris 07 SP, France ED-2009/WS/31. Available at: http://unesdoc.unesco.org/images/0014/001402/140224e.pdf Accessed on: $14 / 11 / 2011$.

University of South Africa (Unisa). 2008. Unisa Community Engagement (CE) and Outreach Policy. www.unisa.ac.za Accessed January 2014.

Watt, D. (2007). On Becoming a Qualitative Researcher: The Value of Reflexivity. The Qualitative Report Vol.12, 1:82-101.

Welman, C, Kruger, F \& Mitchell, B. 2008. Research Methodology. 3rd edition. South Africa: Oxford University Press. 